\title{
Decreased Synthesis of Serum Carboxypeptidase N (SCPN) in Familial SCPN Deficiency
}

\author{
KENNETH P. MATHEWS,${ }^{1}$ JOHN G. CURD,${ }^{2}$ and TONY E. HUGLI ${ }^{2}$
}

\section{Accepted: August 12, 1985}

Serum carboxypeptidase N (SCPN) is the primary inactivator of the $\mathrm{C} 3 \mathrm{a}, \mathrm{C} 4 \mathrm{a}$, and $\mathrm{C} 5 \mathrm{a}$ anaphylatoxins as well as an inactivator of bradykinin. Thus SCPN deficiency potentially could result in significant pathophysiologic consequences. Previous studies identified a deficient subject afflicted with frequent episodes of angioedema, and other family members also had SCPN deficiency. To delineate this abnormality further, the fractional catabolic rate (FRC) and enzyme synthesis were determined in three members of the afflicted kindred as well as in five normal persons following the infusion of homogeneous ${ }^{125}$ I-SCPN. The mean FCR and synthesis rates for SCPN in the normal subjects were $1.3 \% / \mathrm{hr}$ and $20,793 \mathrm{U} / \mathrm{kg} / \mathrm{hr}$, respectively. Reduced synthesis was concluded to be primarily responsible for the low SCPN levels in the afflicted kindred. The high FRC of SCPN discourages attempted maintenance therapy with infusions of enriched SCPN preparations.

KEY WORDS: Serum carboxypeptidase N; anaphylatoxin; angioedema.

\section{INTRODUCTION}

Serum carboxypeptidase N (SCPN), which also is referred to as anaphylatoxin inactivator, kininase $\mathrm{I}$, and serum carboxypeptidase $\mathrm{B}$, is the primary in vivo inactivator of $\mathrm{C} 3 \mathrm{a}, \mathrm{C} 4 \mathrm{a}$, and $\mathrm{C} 5 \mathrm{a}$. The enzyme also inactivates bradykinin, kallidin, fibrinopeptides $A$ and $B$, and plasmin degradation products of fibrin by cleaving the $\mathrm{C}$-terminal cationic amino acid. Postulating that a deficiency in this enzyme might predispose to anaphylactic or anaphylactoid reactions in humans, we have screened more than 500 sera for SCPN activity, with special emphasis on

Division of Allergy, Department of Internal Medicine, University of Michigan Medical School, Ann Arbor, Michigan 48109-0010.

2Department of Molecular Immunology, Research Institute of Scripps Clinic, La Jolla, California 92037. specimens from patients with chronic, idiopathic urticaria/angioedema or persons who have experienced anaphylactoid reactions from radiographic contrast media. As reported previously (1), one individual with chronic, recurrent angioedema and urticaria was identified who had SCPN levels only about $21 \%$ of normal. A sister of the propositus also had low SCPN levels, and other family members had values intermediate between that of the propositus and the normal range. The studies reported here were carried out to determine whether a defect in synthesis or excessive catabolism caused the low SCPN values in the family identified as deficient in SCPN activity. In addition to helping to elucidate the pathophysiologic defect in this kindred, knowledge of the fractional catabolic rate (FCR) would be helpful in assessing the feasibility of maintenance therapy with infusions of enriched SCPN preparations. Thus the FCR and rate of synthesis of SCPN were measured in several normal individuals as well as in the propositus (G.S.), his sister (A.P.), and his son (L.S.).

\section{MATERIALS AND METHODS}

SCPN Purification. SCPN was purified from human plasma by the method of Plummer and Hurwitz (2) and kindly provided to us by Dr. Plummer. It gave a single band on alkaline disc gel electrophoresis and a pattern identical to that previously reported (2) on $7.5 \%$ sodium dodecyl sulfate (SDS) gels following reduction.

$S C P N$ Iodination. A typical procedure consisted of incubating a mixture containing $50 \mu \mathrm{g}$ SCPN in $50 \mu 10.2 M$ phosphate buffer, $\mathrm{pH} 7.2,10 \mu \mathrm{l}^{125} \mathrm{I}(100$ $\mathrm{mCi} / \mu \mathrm{l}$; Amersham), $25 \mu \mathrm{l}$ enzymobeads (Bio-Rad), and $25 \mu \mathrm{l} 1 \% \alpha$-D-glucose in $\mathrm{pH} 7.2$ phosphatebuffered saline (PBS) for $40 \mathrm{~min}$ at room temperature (RT). After adding $50 \mu \mathrm{g}$ SCPN carrier, the mixture was passed through a P10 column to re- 
move free iodide, then eluted with PBS, and fractions containing ${ }^{125} \mathrm{I}-\mathrm{SCPN}$ were pooled; $25 \%$ saltfree human serum albumin (HSA) was added to a final concentration of $1.5 \%$ HSA. After centrifugation in a sterile tube at $150,000 \mathrm{~g}$ for $40 \mathrm{~min}$ at $4^{\circ} \mathrm{C}$, the upper three-fourths of the material was harvested and passed through a sterile $0.45-\mu \mathrm{m}$ Millipore filter into sterile tubes and frozen. Aliquots were cultured and tested for pyrogens in rabbits.

FCR Determination. This protocol was approved by the University of Michigan Medical Center Committee to Review Grants for Clinical Research and Investigation Involving Human Beings, and written informed consent was obtained from all subjects. Preliminarily, a brief history and physical examination, CBC (with hematocrit), ESR, test panel, urinalysis, and serum SCPN determination (3) were obtained. Ten drops of a saturated solution of KI was administered orally on days $-1,0,+1$, and +5 . Following measurements of the vital signs, height and weight, the subjects voided, IV lines were established in both arms, and blood for baseline measurements was obtained via a stopcock in one line. A carefully measured volume of ${ }^{125}$ I-SCPN was injected rapidly into the opposite arm, followed by a rapid wash-in with saline for $10 \mathrm{~min}$. Approximately $12-29 \mu \mathrm{Ci}$ was injected. With accurate timing EDTA-anticoagulated blood was withdrawn through the stopcock at 5,10 , 15,30 , and $60 \mathrm{~min}$. Additional blood samples were obtained at 4,8 , and $24 \mathrm{hr}$ and daily at 8 AM for 7 more days. Urine was collected, measured, and aliquoted at 8,16 , and $24 \mathrm{hr}$ and for 7 days thereafter. On day 7 triplicate aliquots of all plasma and urine specimens were counted on a dual-channel counter together with a residual specimen of the injected ${ }^{125} \mathrm{I}$-SCPN. One normal investigator also was injected simultaneously with an approximately equal number of counts of $\mathrm{Na}^{131}$ I to assess aberrant results caused from loss of the radioactive iodine label.

Data Analysis. Computer programs were employed to analyze the data by the methods of Nosslin (4), Rice, Campbell et al. (5), and Matthews (6). Emphasis was placed on results based on Nosslin's integrated rate equations (method IX), which take into consideration, in addition to plasma counts, urinary isotype recovery and extravascular space volume and turnover. Synthesis rates (SR) were calculated as follows (7):

$$
\mathrm{SR}=\frac{\begin{array}{c}
\mathrm{FCR} \times \text { plasma volume } \\
\times \text { plasma concentration, }
\end{array}}{\mathrm{kg}}
$$

where the plasma volume was estimated from the subject's weight and hematocrit.

Experimental Subjects. These included five volunteer healthy adults (three male, two female), the 67-year-old male SCPN-deficient propositus (G.S.), his 62-year-old SCPN-deficient sister (A.P.), and his 29-year-old son (L.S.), whose SCPN level was more than 2 SD below the mean normal level (about halfway between his father's and the mean normal value).

\section{RESULTS}

Data obtained from a normal subject injected with $\mathrm{Na}^{131} \mathrm{I}$ immediately after injecting ${ }^{125} \mathrm{I}$-SCPN showed a much more rapid clearance of ${ }^{131} I$ than of ${ }^{125} \mathrm{I}$ during the first $4-8 \mathrm{hr}$. This indicates that the results reported were not influenced to a major extent by loss of free iodide from the ${ }^{125} \mathrm{I}-\mathrm{SCPN}$ or degraded ${ }^{125} \mathrm{I}$-SCPN, although the counts of ${ }^{125} \mathrm{I}$ in the urine at $8 \mathrm{hr}$ suggest that this probably occurred to some degree. Based on triplicate plasma ${ }^{125} \mathrm{I}$ counts, Fig. 1 shows the mean values observed in the five normal subjects and individually in the three afflicted family members over the 7-day study period. The data have been normalized to indicate the percentage of initial plasma counts as determined by computer extrapolation to 0 time. It is evident that values for the G.S. family members generally fall within $\pm 2 \mathrm{SD}$ of the mean normal values during the early phase of ${ }^{125} \mathrm{I}$ clearance, but later G.S. and L.S. appear to exhibit slightly more rapid clearance and A.P. somewhat slower clearance than the normal subjects. A more definitive assessment of these data is shown in Table I, which indicates the FCR results calculated by method IX of Nosslin (4). Although falling within the 95\% confidence limits determined by this small group of normal subjects, G.S. has a modestly increased FCR, but A.P. shows a decreased FCR. The calculations also indicate that SCPN is catabolized mainly in the extravascular compartment.

Table I also indicates that the calculated SCPN synthesis rates for G.S. and A.P. both fall well outside the $95 \%$ confidence range for our normal subjects, whereas the value for L.S. is only modestly below the normal mean. Although G.S. has a somewhat higher rate of SCPN synthesis than his sister (A.P.), his higher FCR results in a SCPN level lower than his sibling's. SCPN is expressed in functional units as measured by the method of Corbin et al. (3) since the levels in individual 


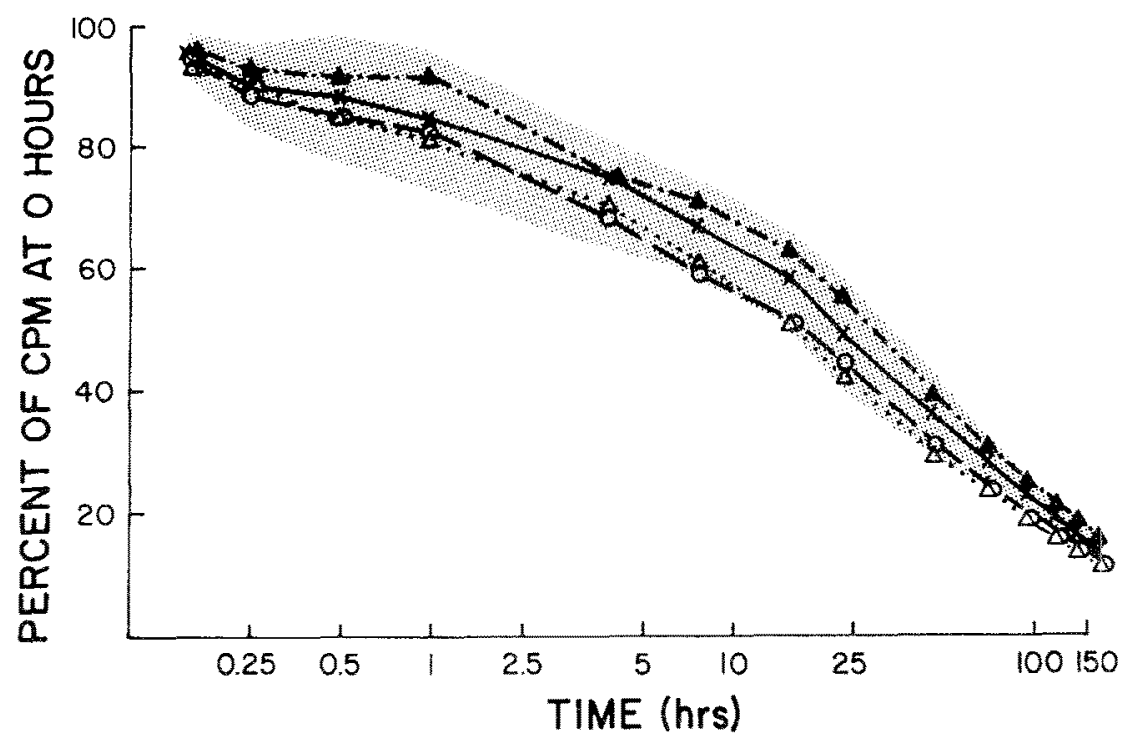

Fig. 1. Percentage of initial plasma ${ }^{125} \mathrm{I} \mathrm{cpm}$ based on measurements of triplicate specimens obtained at the designated time periods, the initial value being a computer extrapolation to time $0 .(X-X)$ The mean of the five normal subjects; the shaded area delineates $\pm 2 \mathrm{SD}$ surrounding these mean values. $(O \ldots O)$ Data for G.S.; $(\Lambda-M)$ data for A.P.; $(\Delta \cdots \Delta)$ data for L.S.

subjects were assessed by this technique. Although it was ascertained that the injected SCPN was biologically active, it is uncertain whether the synthesis rate can be converted into micrograms in the absence of information about whether the purified and native SCPNs have exactly the same specific activity.

\section{DISCUSSION}

It has been presumed that a major SCPN deficiency would be a lethal event in view of its role in inactivating such biologically active substances as

Table I. Fractional Catabolic-Rate and Synthesis-Rate Results

\begin{tabular}{lccc}
\hline & $\begin{array}{c}\text { \% FCR } \\
(\mathrm{hr})\end{array}$ & $\begin{array}{c}\text { Synthesis rate } \\
(\mathrm{U} / \mathrm{kg} / \mathrm{hr})\end{array}$ & $\begin{array}{c}\text { SCPN } \\
(\mathrm{U} / \mathrm{ml})\end{array}$ \\
\hline Normal subjects & & & \\
$\quad$ No. 1 & 1.75 & 28,716 & 377 \\
No. 2 & 1.33 & 16,980 & 289 \\
No. 3 & 0.93 & 13,850 & 300 \\
No. 4 & 1.28 & 18,226 & 342 \\
No. 5 & 1.20 & 26,194 & 322 \\
$\quad$ Mean \pm SD for & & & \\
$\quad$ normal subjects & $1.30 \pm 0.30$ & $20,973 \pm 6,350$ & 326 \\
Patients & & & \\
G.S. (propositus) & 1.76 & 4,678 & 70 \\
A.P. (propositus' & & & \\
$\quad$ Sister) & 0.87 & 3,864 & 75 \\
L.S. (propositus' son) & 1.34 & 15,334 & 160 \\
\hline
\end{tabular}

the anaphylatoxins and kinins. Subnormal levels of SCPN activity have been observed in cord sera (8), in patients with severe liver disease (9), secondary to dextran shock or dengue fever (3), and during hemodialysis (10). The G.S. kindred is the only reported family with a major, inherited SCPN deficiency (1). Although the propositus has been afflicted with about 40 attacks of angioedema/urticaria annually for about the past 20 years, it is of note that he and his sister have survived well into their seventh decade in reasonably good general health. Perhaps this is because they retain at least $20 \%$ of the normal plasma levels of SCPN activity. It is presumed that plasma SCPN is synthesized in the liver, but there also is a possibility that the cell membrane-associated SCPN-type activity, which has been reported to be present in placenta, kidney, pulmonary vascular endothelium, and other tissues, might be a separate source that exerts a significant protective effect $(11,12)$.

The survival of this family with demonstrated SCPN deficiency also prompts reconsideration of the anaphylatoxin inactivation process. Recently it has become apparent that porcine $\mathrm{C} 5 \mathrm{a}_{\text {des arg }}$, the product of SCPN cleavage of C5a, not only retains substantial chemotactic activity but also has nearly as much vascular permeability enhancing and spasmogenic activity in vitro and in vivo as intact C5a (13-15). Thus one might question the essential 
role of SCPN in protecting against the anaphylatoxins in this species. However, the intravenous injection of cobra venom factor into guinea pigs pretreated with a potent SCPN inhibitor results in a rapidly fatal reaction, which features constriction of bronchial and pulmonary vascular smooth muscle. The introduction of cobra venom factor alone fails to produce this dramatic effect, although extensive complement activation occurs (16). Rat $\mathrm{C} 5 \mathrm{a}_{\text {des arg }}$ has greater spasmogenic activity than guinea pig $C 5 \mathrm{a}_{\text {des arg }}$ and is rapidly lethal after intravenous injection into guinea pigs (16). Human $\mathrm{C}^{\mathrm{a}} \mathrm{a}_{\text {des arg }}$ retains about $10 \%$ of the chemotactic activity of C5a, but only about $0.1 \%$ of its other anaphylatoxic activities are retained (15). Thus SCPN deficiency in humans might be expected to enhance more prominently the anaphylactic reactions than inflammatory responses since vasoactive and smooth muscle contracting activity would be markedly increased in plasma during complement activation. At present it is not known how the recently described marked affinity of SCPN for hexapeptide enkephalins (11) might influence manifestations of this enzyme deficiency.

The present data indicate that the major abnormality in G.S. kindred is a markedly reduced rate of SCPN synthesis. This result is consistent with an allelic gene defect, which previous studies of this family (1) have suggested is transmitted as an autosomal recessive trait. Variations in the FCR no doubt influence the SCPN levels but appear to be of secondary importance. It has been suggested that the FCR of this glycoprotein may be influenced by its siliac acid content (17), but we have no data concerning the polysaccharide associated with SCPN in the G.S. kindred. Because of the limited quantity of homogeneous, active SCPN available, it was possible to study only five normal subjects. Although insufficient to define precisely the normal range for FCR and synthesis of SCPN, our data appear representative of a larger population in that the mean SCPN value of $326 \mathrm{U} / \mathrm{ml}$ for our five subjects approximates the mean value of $319 \mathrm{U} / \mathrm{ml}$ which we detrmined previously in a study of 104 normal individuals.

One stimulus for conducting this study was the possibility that the SCPN-deficient patient G.S. might benefit from replacement therapy with partially purified SCPN. Attempts to maintain SCPN at near-normal levels would be feasible, however, only if SCPN has a low FCR, resulting in a substantial half-life in plasma. Unfortunately this did not prove to be the case (Fig. 1). There remains the possibility that this type of treatment might acutely relieve symptoms resulting from SCPN deficiency. This situation in some respects is analogous to hereditary angioedema (HAE), with its attendant deficiency

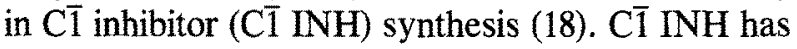
been found to have a relatively high FCR in normal persons and even higher levels in HAE patients (18). Thus maintenance therapy with $\mathrm{C} \overline{1} \mathrm{INH}$ is not feasible, but the intravenous administration of partly purified $\bar{C} \overline{1} \mathrm{INH}$ can produce a prompt remission of symptoms during attacks of HAE (19). There is not a very close analogy between SCPN and CI INH deficiency, in that the former is an enzyme and the latter an inhibitor. In any case, since G.S.'s attacks of angioedema are of fairly short duration and partly relieved by epinephrine administration, treatment of attacks with SCPN-enriched preparations has not been attempted. The patient has not responded to stanozolol therapy.

We conclude that genetic defects in SCPN are rare, and total deficiency may be incompatible with life, perhaps occurring only in infants who fail to survive. Alternatively, total deficiency may be improbable because two sources of the enzyme may exist under separate genetic control: one originates from the liver and the other from cell membraneassociated SCPN-type activity, which has been observed in placenta, kidney, pulmonary vascular endothelium, and other tissues $(11,12)$. The latter scenario would have a decided advantage for survival of the host if SCPN is an essential control enzyme in humans. In any case, the partial SCPN deficiency we have observed in the G.S. kindred presumably led to the development of angioedema/urticaria in the propositus through failure to inactivate anaphylatoxins generated through low levels of complement activation.

\section{ACKNOWLEDGMENTS}

We gratefully acknowledge the gift of homogeneous SCPN from Dr. T. H. Plummer, Jr., and the capable technical assistance of Marleen Kawahara and Pauline M. Pan. This work was supported in part by Grants AI 14950, MOIRR00042, and HL25658 from the NIH.

\section{REFERENCES}

1. Mathews KP, Pan PM, Gardner NJ, Hugli TE: Familial carboxypeptidase $\mathrm{N}$ deficiency. Ann Intern Med 93:443-445, 1980 
2. Plummer TH, Hurwitz MY: Human plasma carboxypeptidase $\mathrm{N}$; Isolation and characterization. $\mathrm{J}$ Biol Chem 253:3907-3912, 1978

3. Corbin NC, Hugli TE, Muller-Eberhard HJ: Serum carboxypeptidase B: A spectrophotometric assay using protamine as substrate. Anal Biochem 73:41-51, 1976

4. Nosslin B: Analysis of disappearance time-curves after single injection of labelled proteins. In Protein Turnover, a Ciba Symposium. New York, Associated Scientific, 1973, pp 113-130

5. Campbell RM, Cuthbertson DP, Matthews CME, McFarlane AS: Behaviour of ${ }^{14} \mathrm{C}$ - and ${ }^{131} \mathrm{I}$-labelled plasma proteins in the rat. Int J Appl Radiat Isol 1:66-84, 1956

6. Matthews CME: Radioisotope techniques in the study of protein metabolism. Int Atom Energy Agency Tech Rep Ser 45:105-118, 1965

7. Krick EH, DeHeer DH, Kaplan RA, Arroyave CM, Vaughan JH: Metabolism of factor $\mathrm{B}$ of serum complement in rheumatoid arthritis. Clin Exp Immunol 34:1-9, 1978

8. Erdos E, Wohler IM, Levine MI, Westerman MP: Carboxypeptidase in blood and other fluids: Values in human blood in normal and pathological conditions. Clin Chim Acta 11:39-43, 1965

9. Bokisch VA, Muller-Eberhard HJ: Anaphylatoxin inactivator of human plasma: Its isolation and characterization as a carboxypeptidase. J Clin Invest 49:2427-2436, 1970

10. McCormick JR, Kreutzer DL, Keating HJ, Hupp J, Despins A, Moore M: Alterations in activities of anaphylatoxin inactivator and chemotactic factor inactivator during hemodialysis. Am J Pathol 109:283-287, 1982

11. Skidgel RA, Johnson AR, Erdos EG: Hydrolysis of opoid hexapeptides by carboxypeptidase N. Presence of carboxypeptidase in cell membranes. Biochem Pharmacol 33:34713478,1984

12. Ryan JW, Ryan US: A radioassay for carboxypeptidase N. Adv Exp Med Biol 156 (Pt B):867-874, 1983

13. Stimler NP, Brocklehurst WE, Bloor CM, Hugli TE: Anaphylatoxin-mediated contraction of guinea pig lung strips: A nonhistamine tissue response. J Immunol 126:2258-2261, 1981

14. Stimler NP, Hugli TE, Bloor CM: Pulmonary injury induced by C3a and C5a anaphylatoxins. Am J Pathol 100:327-348, 1980

15. Gerard C, Hugli TE: C5a: A mediator of chemotaxis and cellular release reactions. In Biochemistry of the Acute Allergic Reactions, Kroc Foundation Series, Vol 14, EL Becker, AS Simons, KF Austen (eds). New York, Alan R. Liss, 1981, pp 147-160

16. Huey R, Bloor CM, Kawahara MS, Hugli TE: Potentiation of the anaphylatoxins in vivo using an inhibitor of serum carboxypeptidase $\mathrm{N}$ (SCPN). I. Lethality and pathologic effects on pulmonary tissue. Am J Pathol 112:48-60, 1983

17. Koheil A, Forstner G: Isoelectric focusing of carboxypeptidase N. Biochem Biophys Acta 524:156-161, 1978

18. Quastel M, Harrison R, Cicardi M, Alper CA, Rosen FS: Behavior in vivo of normal dysfunctional $\mathrm{C} 1$ inhibitor in normal subjects and patients with hereditary angioneurotic edema. J Clin Invest 71:1041-1046, 1983

19. Gadek JE, Hosea SW, Gelfand JA, Santella M, Wickerhauser M, Triantaphyllopoulos DC, Frank MM: Replacement therapy in hereditary angioedema: successful treatment of acute episodes of angioedema with partly purified C1 inhibitor. N Engl J Med 302:542-546, 1980 